\title{
Investigations on the Timing of Fruit Infection by Fungal Pathogens Causing Fruit Rot of Deciduous Holly
}

\author{
Shan Lin and Francesca Peduto Hand, ${ }^{\dagger}$ Department of Plant Pathology, The Ohio State University, Columbus, 43210
}

\begin{abstract}
Fruit rot of deciduous holly is an emerging fungal disease that is affecting plant production across midwestern and eastern U.S. nurseries. To determine the growth stage(s) of host susceptibility to infection by the major pathogens associated with the disease, Alternaria alternata and Diaporthe ilicicola, and minor pathogens such as Colletotrichum fioriniae and Epicoccum nigrum, we conducted two sets of experiments over two consecutive seasons. In the first case we monitored the presence of the pathogens as well as disease progression in a commercial nursery under natural conditions by collecting plant tissues from the flower bud stage until fruit maturity. The target pathogens were consistently isolated from asymptomatic samples at all stages of fruit development and from symptomatic samples at fruit maturity across the 2 years of collection. A significant increase in fungal isolation frequency, primarily species of Alternaria and Colletotrichum, was observed right after flowering, but fruit rot symptoms only developed on mature fruit. In the second case we artificially inoculated

containerized plants maintained outdoor at our research farm with individual or combined pathogens at different fruit developmental stages, and we assessed disease incidence on mature fruit to determine the time of host susceptibility to infection and, indirectly, whether pathogens in the fungal complex carry out latent infections. $D$. ilicicola could cause latent infection on deciduous holly fruit when inoculated at the full bloom and petal fall stages, and all inoculations made on wounded mature fruit resulted in fruit rot. These findings suggest that flowering represents a critical period to manage $D$. ilicicola infections and that mature fruit should be protected from any injury to avoid disease. In both experiments a negative correlation between disease incidence and temperature was found; however, the decrease in temperature also coincided with fruit ripening. The effects of temperature and changes in physiological properties of the fruit during maturation on disease development should be further investigated to fully interpret these findings.
\end{abstract}

Deciduous hollies (Ilex spp. L.) are dioecious ornamental shrubs popularly used in the cut flower industry (Galle 1997). Their branches carrying brightly colored fruit are harvested in late fall to be used in winter holiday decorations, representing an important source of revenue for nursery growers in a period of the year in which business is otherwise at low ebb. We previously reported that deciduous holly production in midwestern and eastern U.S. nurseries has been affected in recent years by a fruit rot causing plant material to become unsalable (Lin et al. 2018). The disease is characterized by a variety of symptoms, including early plant defoliation and production of fruit that is undersized, loses its gloss, fails to turn color, shrivels, and eventually becomes rotten (Lin et al. 2018).

Disease management recommendations should rely on knowledge of the disease-causing agents as well as of disease epidemiology. Previous studies conducted over multiple years and across different locations have revealed that a fungal complex is associated with this disease (Lin et al. 2018). Alternaria alternata (Fr.) Keissl. and a recently described Diaporthe Nitschke species, namely, Diaporthe ilicicola S. Lin, Taylor \& Peduto Hand, were identified as the primary pathogens. Several other fungal species, including Alternaria arborescens E. G. Simmons, Colletotrichum fioriniae (Marcelino \& Gouli) Pennycook, C. nymphaeae (Pass.) Aa, fungi in the D. eres Nitschke

${ }^{\dagger}$ Corresponding author: F. Peduto Hand; E-mail: hand.81@osu.edu

Funding: This study was supported by the Ohio Department of Agriculture through the Specialty Crop Block Grant Program at the U.S. Department of Agriculture through grants AGR-SCG-14-08 and AGR-SCG-16-09, the USDA-NIFA Hatch project \#1004939, the T. J. Kavanagh Foundation, and The Ohio State University Department of Plant Pathology.

Disclaimer: This publication was financed in part or totally through a grant from the Ohio Department of Agriculture, the State of Ohio, and the United States Department of Agriculture under the provisions of the Specialty Crop Block Grant. Its contents are solely the responsibility of the authors and do not necessarily represent the official views of the USDA.

Accepted for publication 7 August 2018.

() 2019 The American Phytopathological Society species complex, and Epicoccum nigrum Link, were identified as minor pathogens (Lin et al. 2018). Although all these pathogens were isolated to a greater or lesser extent from mature holly fruit at or around the time of branch harvest (late fall), it is not known exactly when in the growing season fruit infections may occur.

Bud break of deciduous holly occurs in early spring and is followed by formation of leaves. Flowers are produced in mid- to late spring, and the blooming period lasts between 10 and 14 days, depending on the species and cultivar (Galle 1997). After petal fall occurs, the fruit starts to develop, turning color in early fall and being fully mature by mid-fall (Galle 1997). Some of the pathogens involved in the fungal complex have been extensively studied on other crops to understand which growth stage or stages of the host are susceptible to infection. It has been reported that infections caused by $A$. alternata on apple, mango, mandarin, persimmon, Pingguoli pear (Pyrus bretschneideri), and sweet pepper could occur at different stages of fruit development, from bloom until fruit maturation (Halfon-Meiri and Rylski 1983; Harteveld et al. 2014; Li et al. 2007; Nemsa et al. 2012; Prusky et al. 1981, 1983). Likewise, several species of Colletotrichum and Diaporthe have been reported to be able to infect almond, blueberry, mango, melon, and peach from the flowering stage until fruit maturation (Adaskaveg and Hartin 1997; Binyamini and Schiffmann-Nadel 1972; Daykin and Milholland 1984; Johnson et al. 1992; McKay et al. 2014; Ohsawa and Kobayashi 1989; Verma et al. 2007; Zaitlin et al. 2000).

No study has been yet conducted to identify the factors contributing to the development of fruit rot on deciduous holly. However, proper identification of all the components of the disease triangle, including factors related to the susceptibility of the host to infection, is needed to fully understand this disease and provide holly growers with research-based recommendations for effective disease management. To this extent, the specific objective of this study was to determine the growth stage or stages of deciduous holly fruit that are susceptible to infection by different pathogens in the fungal complex.

\section{Materials and Methods}

Assessment of fruit stage susceptibility under nursery conditions. A field survey was conducted in 2016 and 2017 in a nursery in Wooster, $\mathrm{OH}$, which was exposed to natural pathogen inoculum and in which fruit rot had been observed yearly since 2014. Plant material included 
the deciduous holly hybrid Ilex verticillata $\times$ Ilex serrata 'Bonfire', which was previously reported as being susceptible to fruit rot (Lin et al. 2018). The surveyed area of the nursery comprised 20 trees, which were located in one individual row within a production field that had been established in 1994. No management practices were carried out in the entire nursery, including the experimental plot, at any point of the growing season throughout the duration of the experiments. Plants were sampled weekly or biweekly from May to December of each year at five different stages of fruit development to assess infection and monitor for disease symptom development. The aforementioned five stages, the corresponding sampling periods of each year, and the combined total number of samplings are defined as follows: stage 1 (flower bud) $=$ more than $90 \%$ of flower buds fully developed, with expanded petals that are white but still closed (from May 27 to June 9, 2016, and from May 26 to June 9, 2017; total samplings $=6$ ); stage 2 (full bloom) $=$ more than $90 \%$ of flowers open (June 16, 2016, and June 16, 2017; total samplings $=2$ ); stage 3 (petal fall) = petals of more than $90 \%$ of flowers fallen and small green fruit set (June 23, 2016, and June 23, 2017; total samplings =2); stage 4 (immature fruit) $=$ fruit from 1 to $2 \mathrm{~mm}$ to 6 to $8 \mathrm{~mm}$ in diameter and not completely red (from June 30 to September 21, 2016, and from June 30 to September 29, 2017; total samplings = 27); and stage 5 (mature fruit) = fruit fully developed and completely red (from September 29 to December 1, 2016, and from October 6 to December 1, 2017; total samplings = 17). On each sampling date, 10 individual plant tissues (i.e., flower buds, flowers, or fruit) were randomly collected from the entire canopy of each tree in the experimental plot to maximize randomization and then pooled together inside a plastic bag. Samples were then transported to the laboratory inside a cooler and stored at $4{ }^{\circ} \mathrm{C}$ for a maximum of $24 \mathrm{~h}$ before being processed. One hundred plant tissues were randomly extracted from the bag and processed as described herein: samples collected from stage 1 through 3 were surface disinfected for $90 \mathrm{~s}$ with $0.5,0.5$, and $1 \%$ household bleach (6\% sodium hypochlorite; The Clorox Company, Oakland, CA), respectively. Samples were then rinsed in sterile water three times and placed on a sterile paper towel inside a laminar flow hood to allow air drying. Each plant tissue was then plated on potato dextrose agar (PDA; Difco Laboratories, Sparks, MD) amended with $0.1 \%$ lactic acid, $0.01 \%$ tetracycline hydrochloride, and $0.015 \%$ streptomycin sulfate (Fisher Scientific, Fair Lawn, NJ), and plates were incubated on a laboratory bench at $25^{\circ} \mathrm{C}$ for up to 10 days. Fungal colonies developing from the tissues were counted, and any fungal growth was subcultured onto a new PDA plate. Pure cultures of each isolate were obtained by transferring hyphal tips from the margin of the fungal colonies onto new PDA plates. All isolates were then preserved as mycelial plugs in sterile distilled water at $4^{\circ} \mathrm{C}$ (Humber 1997). All isolates were tentatively identified to species using morphological features (Barnett and Hunter 1998; Baumgartner et al. 2013; Dissanayake et al. 2015; Lin et al. 2018; Mahadevakumar et al. 2014; Shivas and Tan 2009; Simmons 2007; Udayanga et al. 2014; Velho et al. 2015; Wu et al. 2017). To confirm species identification, at least half of the isolates collected at each stage of fruit development that showed similar morphology were randomly selected and subject to molecular characterization as described in Lin et al. (2018).

Fruit collected from stage 4 through 5 were visually inspected for symptoms of fruit rot, and disease incidence and severity were recorded from each fruit. Fruit rot incidence was assessed as presence or absence of symptoms on each fruit, and disease severity was assessed as the percentage of fruit surface area affected. Total disease incidence and severity were then calculated for each sampling time. Subsequently, fruit was sorted into two groups: symptomatic and asymptomatic. Fungal isolation from the lesions on symptomatic fruit and culture identification were conducted as described in Lin et al. (2018). Asymptomatic fruit were surface disinfected as previously described but by using $2 \%$ household bleach (6\% sodium hypochlorite; The Clorox Company) for $2 \mathrm{~min}$. Once dry, fruit were cut in half and plated cut-side down on V8 juice agar (Olatinwo et al. 2003) rather than PDA to facilitate growth of slower-growing fungi. Plate incubation conditions and the identification and preservation of fungal colonies developing from the asymptomatic tissue were the same as previously described.

Container trial locations and experimental design. An outdoor container trial was established at The Ohio State University Agricultural and Natural Resources Laboratory (Waterman Farms) in Columbus, $\mathrm{OH}$, to conduct artificial inoculations with the fungal pathogens associated with fruit rot of deciduous holly and assess the timing of fruit infection. Experiments were conducted over two consecutive growing seasons (2016 to 2017) from spring to late fall (from April 19 through December 10, 2016, and from April 26 through December 8, 2017). Plant material included 2-year-old (2016) or 3-year-old (2017) plants of I. verticillata $\times$ I. serrata female cultivar Sparkleberry, and male pollinator cultivars Apollo, Jim Dandy, and Southern Gentleman, which were placed among females to facilitate pollination. All plants were maintained in 3-gal nursery containers containing a mix of 10 to $15 \%$ Com-Til and 85 to $90 \%$ pine bark (Kurtz Bros., Columbus, $\mathrm{OH}$ ). Plants were fertilized at the time of trial establishment with $55 \mathrm{~g}$ of Osmocote 14-14-14 (Everris NA, Dublin, $\mathrm{OH}$ ) and watered as needed throughout the duration of the trial by a drip irrigation system. Plants were arranged in rows in a randomized complete block design with six blocks. Rows were $15 \mathrm{~m}$ long and $0.3 \mathrm{~m}$ apart. In 2016, when plants were younger, two Sparkleberry plants per treatment were included in each block and were treated as a single experimental unit (average fruit number =91). In 2017, plants grew bigger and only one plant per treatment was included in each block (average fruit number $=101$ ). Between seasons (December 2016 through April 2017), plants were overwintered in a covered polyhouse.

Container trial inoculations and data collection. Isolates of $A$. alternata, $C$. fioriniae, D. ilicicola, and $E$. nigrum originally isolated from symptomatic holly fruit and whose virulence was previously confirmed through the fulfillment of Koch's postulates (Lin et al.

Table 1. Fungal isolates used to inoculate plants in the container trial in 2016 and 2017

\begin{tabular}{|c|c|c|c|c|}
\hline Fungal species & Isolate number & Origin & Year of isolation & Reference \\
\hline \multirow[t]{7}{*}{ Alternaria alternata } & FPH2015416 & Ohio & 2015 & Lin et al. (2018) \\
\hline & FPH2015419 & Ohio & 2015 & Lin et al. (2018) \\
\hline & FPH2015468 & Ohio & 2015 & Lin et al. (2018) \\
\hline & FPH2015507 & Ohio & 2015 & Lin et al. (2018) \\
\hline & FPH2015508 & Ohio & 2015 & Lin et al. (2018) \\
\hline & FPH2015593 & Ohio & 2015 & Lin et al. (2018) \\
\hline & FPH2015597 & Ohio & 2015 & Lin et al. (2018) \\
\hline \multirow[t]{2}{*}{ Colletotrichum fioriniae } & FPH2015466 & Ohio & 2015 & Lin et al. (2018) \\
\hline & FPH2015564 & Ohio & 2015 & Lin et al. (2018) \\
\hline \multirow[t]{4}{*}{ Diaporthe ilicicola } & FPH2015473 & Ohio & 2015 & Lin et al. (2018) \\
\hline & FPH2015502 & Ohio & 2015 & Lin et al. (2018) \\
\hline & FPH2015509 & Ohio & 2015 & Lin et al. (2018) \\
\hline & FPH2015598 & Ohio & 2015 & Lin et al. (2018) \\
\hline \multirow[t]{2}{*}{ Epicoccum nigrum } & FPH2015417 & Ohio & 2015 & Lin et al. (2018) \\
\hline & FPH2015505 & Ohio & 2015 & Lin et al. (2018) \\
\hline
\end{tabular}


2018) were used in the container trials and are listed in Table 1. Inoculum was prepared by flooding 2- to 4-week-old PDA cultures using a sterile distilled water/Tween 20 solution $(0.05 \% \mathrm{v} / \mathrm{v})$ and by adjusting the concentration to $10^{5}$ conidia/ml using a hemocytometer. Inoculum of each pathogen species was obtained by combining spore suspensions from all isolates (2 to 7) of each species (Table 1).

In 2016, only individual pathogen species inoculum was used in the experiments, whereas in 2017 , additional treatments were included to assess the effects of combined pathogens on disease development. The additional treatments in 2017 were obtained by combining inoculum of two pathogens (i.e., A. alternata $+C$. fioriniae; A. alternata $+D$. ilicicola $;$ and A. alternata + E. nigrum; 1:1 $\mathrm{v} / \mathrm{v}$ ), each initially prepared as previously described. In 2016, plants at the fruit development stage 1 (flower bud), 2 (full bloom), 3 (petal fall), 4 (immature fruit), and 5 (mature fruit) were inoculated on June 3 , June 14, June 26, August 17, and October 11, respectively. In 2017, inoculation dates from stage 1 to 5 were May 30, June 5, June 13, August 16, and October 10, respectively. At stage 5, a subset of fruit was wounded using a sterile needle prior to inoculation to determine the effects of wounding on infection. Prior to each inoculation, plants from the appropriate treatments were moved inside a head house, and plant tissues that were not at the specific inoculation stage were removed (e.g., newly developed flowers on plants to be inoculated at stage 4). On the inoculation day, every flower bud (stage 1), flower (stage 2 and 3), or fruit (stage 4 and 5) on each plant was point inoculated using a micropipette with a volume of the different spore suspensions that could be held on the tissue without dropping (i.e., $6 \mu l$ on stage 1 to $3 ; 12 \mu l$ on stage 4 to 5 ). In the case of wounded fruit at stage 5 , a drop of spore suspension was placed directly on the wound. In all cases, inoculum was allowed to dry on the inoculated tissues for approximately $15 \mathrm{~min}$ to prevent dislodging the spore suspension droplets. Subsequently, plants were enclosed in a plastic bag and kept in a climatized head house at $25 \pm 2{ }^{\circ} \mathrm{C}$ for $24 \mathrm{~h}$ to favor infection prior to being moved back in the outdoor trial. A subset of fruit at stage 5 in the control group was wounded using a sterile needle and inoculated with sterile distilled water to serve as controls. Owing to space limitations, only one set of control plants was used for all inoculation stages. These plants remained undisturbed and noninoculated in the trial throughout the duration of the experiments. Incidence of fruit rot in each treatment was evaluated weekly (from June 26 to December 7, 2016, and from June 13 to December 5,2017 ) by recording the number of fruit exhibiting rot symptoms in each plant. Reisolation of the inoculated pathogen from the symptomatic fruit and isolate identification were carried out as previously described (Lin et al. 2018).

Meteorological data. Meteorological data, including minimum, maximum, and average daily temperature as well as precipitation, were downloaded from the USDA-ARS weather research network (http:// www.oardc.ohio-state.edu/weather1/) available for Columbus and Wooster, OH, for the entire disease assessment period (2016 to 2017).

Statistical analysis. Frequency of fungal isolation from asymptomatic plant tissues collected from the nursery was calculated for each sampling stage. To test the effects of stages of fruit development (stage 1 to 5) on fungal isolation frequency, a repeated-measures analysis of variance (ANOVA) was performed for each individual pathogen. All data were arcsine transformed and analyzed using PROC GLIMMIX in SAS (version 9.4; SAS Institute, Cary NC) and then back-transformed to present results. The number of samplings, which differed for each fruit developmental stage, was specified in the WEIGHT option. The stage of fruit development was treated as a fixed factor, whereas the year was treated as a random factor. Least squares means $(\alpha=0.05)$ were used for comparisons among different stages. As far as the container trial is concerned, fruit rot incidence data from the final disease assessment in both 2016 and 2017 were subject to one-way ANOVA. Each inoculation stage was analyzed independently using PROC GLM in SAS (version 9.4; SAS Institute). Tukey's honestly significant difference test was used for mean separation among treatments $(\alpha=0.05)$.

Mean minimum, maximum, and average daily temperatures and accumulated precipitation between consecutive disease assessment dates were calculated for both nursery and container trials from the period of 1 week before the onset of symptoms until the last disease assessment. Pearson's correlation test $(\alpha=0.05)$ was used to analyze correlation between different meteorological factors and disease incidence using PROC CORR in SAS (version 9.4; SAS Institute).

\section{Results}

Assessment of fruit stage susceptibility under nursery conditions. From 2016 to 2017, a total of 600 flower buds, 200 flowers, and 4,819 fruit (4,507 asymptomatic and 312 symptomatic)

Table 2. Frequency of fungal isolation (\%) from asymptomatic and symptomatic samples collected from the nursery at different stages of fruit development from 2016 to 2017

\begin{tabular}{|c|c|c|c|}
\hline \multirow[b]{2}{*}{ Pathogen } & \multirow[b]{2}{*}{ Stage of fruit development } & \multicolumn{2}{|c|}{ Isolation frequency $(\%)^{\mathrm{w}}$} \\
\hline & & Asymptomatic samples & Symptomatic samples \\
\hline \multirow[t]{5}{*}{ Alternaria } & 1 & $4.16 \mathrm{a}^{\mathrm{x}}$ & $\mathrm{NA}^{\mathrm{y}}$ \\
\hline & 2 & $23.53 \mathrm{a}$ & NA \\
\hline & 3 & $29.58 \mathrm{a}$ & $-^{\mathrm{z}}$ \\
\hline & 4 & $76.75 \mathrm{~b}$ & - \\
\hline & 5 & $85.83 \mathrm{~b}$ & 3.85 \\
\hline \multirow[t]{5}{*}{ Diaporthe } & 1 & $12.98 \mathrm{a}$ & NA \\
\hline & 2 & $18.50 \mathrm{a}$ & NA \\
\hline & 3 & $11.98 \mathrm{a}$ & - \\
\hline & 4 & $11.14 \mathrm{a}$ & - \\
\hline & 5 & $14.13 \mathrm{a}$ & 25.64 \\
\hline \multirow[t]{5}{*}{ Colletotrichum } & 1 & $0.08 \mathrm{a}$ & NA \\
\hline & 2 & $0.25 \mathrm{ab}$ & NA \\
\hline & 3 & $0.00 \mathrm{a}$ & - \\
\hline & 4 & $3.36 \mathrm{~b}$ & - \\
\hline & 5 & $4.38 \mathrm{~b}$ & 0.32 \\
\hline \multirow[t]{5}{*}{ Epicoccum } & 1 & $3.82 \mathrm{a}$ & NA \\
\hline & 2 & $18.45 \mathrm{ab}$ & NA \\
\hline & 3 & $26.50 \mathrm{ab}$ & - \\
\hline & 4 & $42.26 \mathrm{~b}$ & - \\
\hline & 5 & $68.21 \mathrm{~b}$ & 2.88 \\
\hline
\end{tabular}

\footnotetext{
${ }^{\mathrm{w}}$ Columns represent the value of pooled data across years of observation $(n=2)$.

$\mathrm{x}$ Values with the same letter within each pathogen are not significantly different according to least squares means multiple comparisons $(\alpha=0.05)$.

y $\mathrm{NA}=$ not applicable.

$\mathrm{z}$ The negative sign (-) indicates that no symptoms were observed on the fruit at the specific stage.
} 
at different developmental stages were collected and processed. Multiple fungi, including species of Alternaria, Diaporthe, Colletotrichum, Epicoccum, Botrytis P. Micheli ex Haller, Cladosporium Link, Fusarium Link, Pestalotia De Not., Phoma Sacc., and fungi in the Botryosphaeriaceae Theiss. \& P. Syd., were isolated from the plant tissues. Among these, species of Alternaria, Diaporthe, and Epicoccum were consistently isolated from asymptomatic samples at all stages of fruit development (1 through 5; Table 2). With the exclusion of stage 3, species of Colletotrichum were also consistently isolated from these samples (Table 2). Based on morphological and molecular identification of selected isolates of Alternaria $(n=27)$, Diaporthe $(n=27)$, Colletotrichum $(n=15)$, and Epicoccum $(n=26)$, recovered from asymptomatic tissues, the most prevalent species included A. alternata, A. arborescens, C. fioriniae, C. nymphaeae, D. ilicicola, fungi in the D. eres species complex, and E. nigrum (data not shown). In general, the isolation frequency of all four fungal genera increased along with the progression of fruit development and maturation (Table 2). When fruit became mature (stage 5), species of Alternaria and Epicoccum had higher isolation frequency from asymptomatic fruit $(85.83$ and $68.21 \%$, respectively), followed by Diaporthe (14.13\%) and Colletotrichum (4.38\%; Table 2). For Alternaria and Colletotrichum, a significant increase in isolation frequency was observed from stage 3 to 4 , whereas for Epicoccum, it increased significantly from stage 1 to 4 . No significant difference in isolation frequency was observed for Diaporthe (Table 2).
In both 2016 and 2017, fruit rot symptoms were first observed in November (average temperature 5.5 and $6.5^{\circ} \mathrm{C}$, respectively) when the fruit was fully mature (stage 5). Symptoms mostly developed from the side of the fruit corresponding to the location of the stigma on the flower. Less frequently, symptoms were observed from the corresponding calyx and from the lenticels naturally distributed on the fruit surface (Fig. 1). Diaporthe spp. had the highest isolation frequency $(25.64 \%)$ from symptomatic fruit, followed by species of Alternaria, Epicoccum, and Colletotrichum (Table 2). The disease incidence from the final disease assessment was 40 and $60 \%$ in 2016 and 2017, respectively, whereas severity was 21.78 and $48.21 \%$, respectively. Frequently, it was observed that a combination of factors (e.g., insect and bird activity, hail, etc.) caused wounds to form on mature fruit (stage 5). Occasionally, rot symptoms developed from the wounds and species of Alternaria and Epicoccum were isolated (data not shown).

In 2016, a negative correlation between mean maximum temperature and disease incidence was observed. No significant correlation was observed between other meteorological factors and disease incidence (Table 3).

Container trials. Fruit rot symptoms were first observed in the container trials at the beginning of November 2016 (average temperature $12.8^{\circ} \mathrm{C}$ ) and at the end of October 2017 (average temperature $15.6^{\circ} \mathrm{C}$ ). In both years, symptoms developed on fruit inoculated with $D$. ilicicola at stages 2 and 3 and on fruit inoculated with all pathogens at stage 5 , but
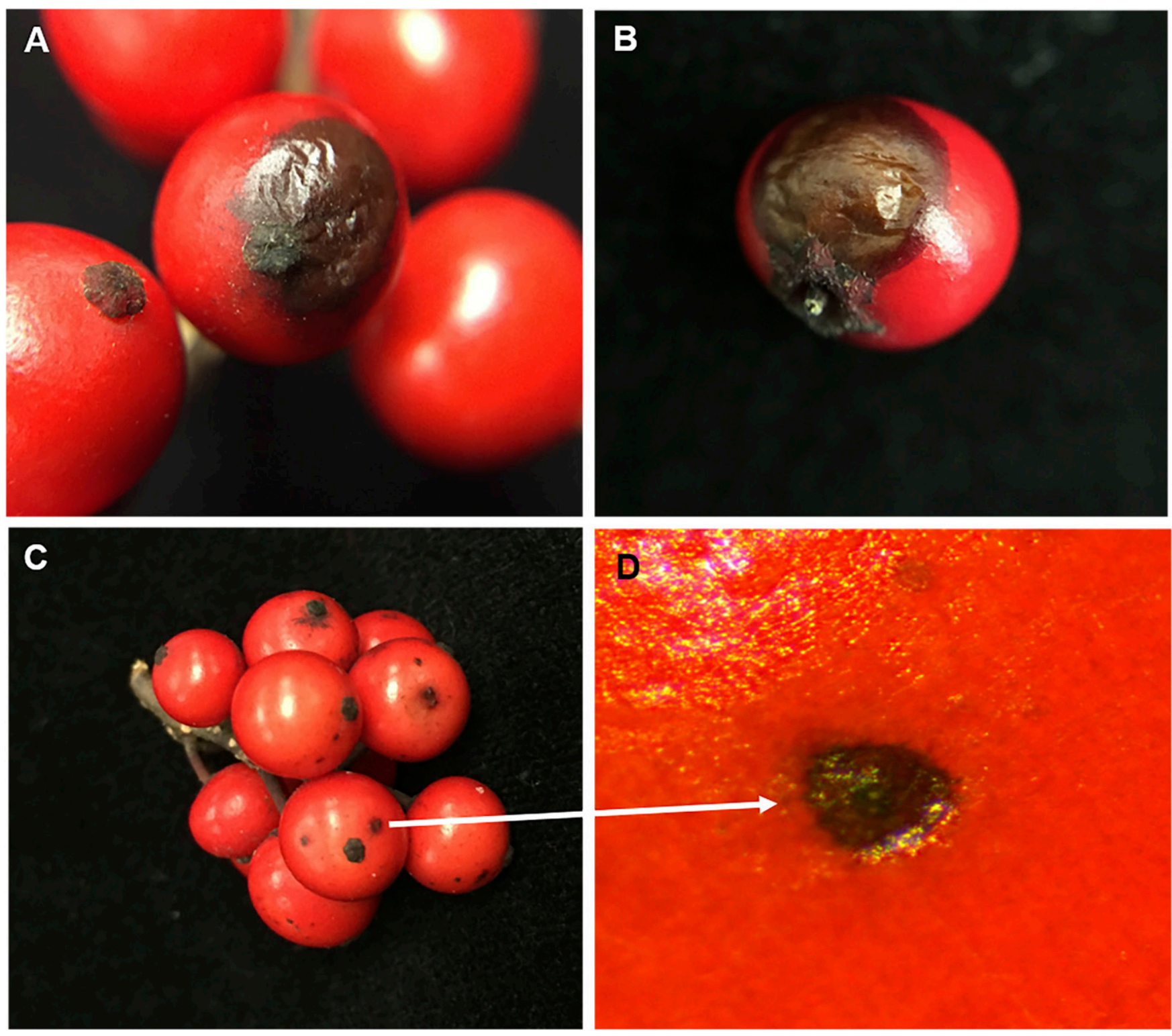

Fig. 1. Rot symptoms on mature holly fruit developing from the stigmatic end (A), calyx end (B), and lenticels (C and D). 
only on the wounded treatments (Fig. 2). Symptoms developed from the side of the fruit corresponding to the location of the stigma on the flower when inoculated at stages 2 and 3, or from the wound when inoculated at stage 5. In 2017, fruit inoculated with the combined D. ilicicola + A. alternata inoculum at stages 2 and 3 also developed symptoms (Fig. 2). However, disease incidence was significantly lower than on fruit inoculated with D. ilicicola only at the same inoculation stages. Disease incidence on wounded fruit inoculated at stage 5 ranged from 25.47 to $68.54 \%$, with E. nigrum or A. alternata + E. nigrum showing significantly lower values (Fig. 2). An average of 1.15 and $2.61 \%$ of wounded fruit at stage 5 from noninoculated control plants developed rot symptoms in 2016 and 2017, respectively (Fig. 2), and species of Alternaria and Epicoccum were retrieved from the lesions. No disease was observed on unwounded fruit from noninoculated control plants in either year.

In both 2016 and 2017, disease incidence in all symptomatic treatments was negatively correlated to mean maximum and average temperatures (Table 3). In 2017, disease incidence in symptomatic treatments inoculated at stage 2 or 3 was also negatively correlated to mean minimum temperature (Table 3 ). No significant correlation was observed between accumulated precipitation and disease incidence (Table 3 ).

\section{Discussion}

Fruit rot of deciduous holly is an emerging disease that is affecting plant production across midwestern and eastern U.S. nurseries. Several fungal pathogens, including A. alternata, A. arborescens, D. ilicicola, $C$. fioriniae, $C$. nymphaeae, E. nigrum, and fungi in the $D$. eres species complex, were found to be the disease causal agents (Lin et al. 2018). To advance our understanding of this disease, in this study we focused on identifying the timing of host susceptibility to infection by the fungal pathogens by monitoring the presence of the disease causal agents in the fruit at different stages of development (from flower bud to mature fruit) as well as disease progression on plants exposed to natural inoculum (i.e., nursery assessment) or artificially inoculated (i.e., container trials).

In the nursery, the disease causal agents were consistently isolated from asymptomatic samples with isolation frequency increasing along with the progression of fruit development and maturation. At

Table 3. Correlation between disease incidence and environmental variables in the nursery and container trials in 2016 and 2017

\begin{tabular}{|c|c|c|c|c|c|}
\hline \multirow[b]{2}{*}{ Experiment } & \multirow[b]{2}{*}{ Correlation factor ${ }^{x}$} & \multicolumn{4}{|c|}{ Pearson correlation coefficient $(r)^{\mathbf{y}, \mathbf{z}}$} \\
\hline & & $\mathbf{P}$ & $\operatorname{Max}^{\circ}{ }^{\circ} \mathrm{T}$ & Min. ${ }^{\circ} \mathbf{T}$ & Avg. ${ }^{\circ} \mathrm{T}$ \\
\hline \multirow[t]{2}{*}{ Nursery } & 2016 & & -0.98 & & \\
\hline & 2017 & & & & \\
\hline \multirow[t]{6}{*}{ Container trial } & 2016 Diaporthe ilicicola (stage 2) & & -0.86 & & -0.83 \\
\hline & 2016 D. ilicicola (stage 3$)$ & & -0.85 & & -0.89 \\
\hline & 2017 D. ilicicola $($ stage 2$)$ & & -0.82 & -0.83 & -0.83 \\
\hline & $\begin{array}{l}2017 \text { D. ilicicola }+ \text { Alternaria alternata (stage } \\
\text { 2) }\end{array}$ & & -0.79 & -0.80 & -0.79 \\
\hline & 2017 D. ilicicola $($ stage 3$)$ & & -0.79 & -0.83 & -0.81 \\
\hline & 2017 D. ilicicola + A. alternata $($ stage 3$)$ & & -0.80 & -0.84 & -0.83 \\
\hline
\end{tabular}

${ }^{x}$ Disease incidence observed each year in the nursery trials or according to the different inoculation treatments that resulted in symptomatic fruit in the container trials.

${ }^{\text {y }} \mathrm{P}=$ accumulated precipitation $(\mathrm{mm}) ;$ Max. ${ }^{\circ} \mathrm{T}=$ mean maximum temperature $\left({ }^{\circ} \mathrm{C}\right)$; Min. ${ }^{\circ} \mathrm{T}=$ mean minimum temperature $\left({ }^{\circ} \mathrm{C}\right) ;$ and $\mathrm{Avg} .{ }^{\circ} \mathrm{T}=$ mean average temperature $\left({ }^{\circ} \mathrm{C}\right)$.

${ }^{\mathrm{z}}$ Blank column $=$ not significant $(P>0.05)$.

2016
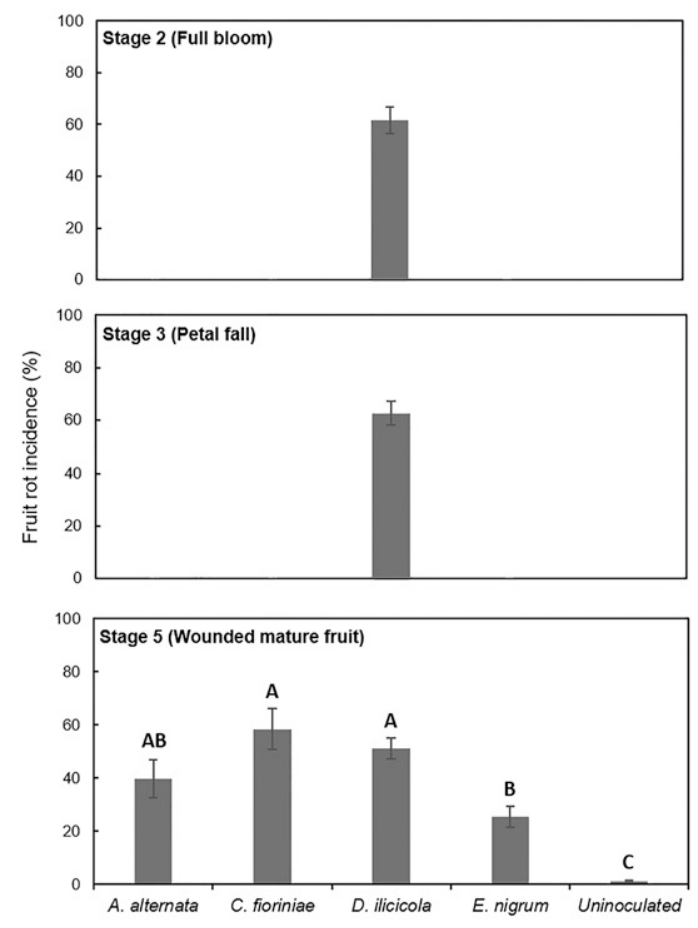

2017
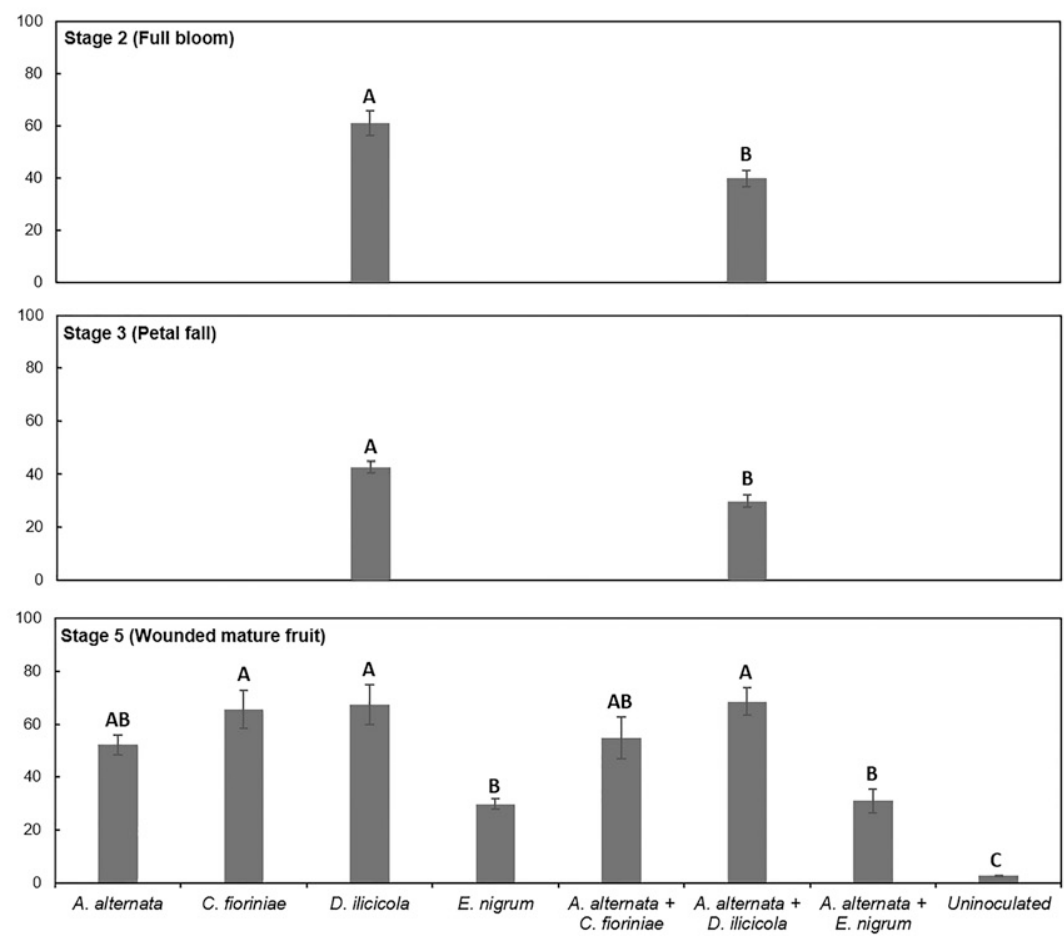

Fig. 2. Stages of plant inoculation in the container trial that resulted in symptomatic fruit in 2016 and 2017 , and corresponding disease incidence. Values with the same letter within the same inoculation timing are not significantly different according to Tukey's honestly significant difference test $(\alpha=0.05)$. Bars indicate standard error of the mean. 
stage 5 (mature fruit), Alternaria spp. had the highest isolation frequency from asymptomatic fruit but relatively lower frequency of isolation from symptomatic fruit compared with Diaporthe spp. Isolation frequency of different pathogens may vary in a given location based on the presence of relative inoculum, which may be influenced by the history of disease management practices, the presence of alternate hosts, and environmental factors (Harteveld et al. 2014; Holb and Scherm 2007; McKay et al. 2014; Moral and Trapero 2012). Although only one nursery was included in this study, a more extensive sampling of symptomatic fruit conducted over multiple years and locations revealed that these two genera are equally associated with diseased fruit ( $\mathrm{Lin}$ et al. 2018). A survey to determine the relative distribution of different species in a specific nursery could be valuable to optimize the design of disease management strategies.

Disease incidence and severity in the nursery were lower in 2016 compared with 2017. This may have been owing to less pathogen inoculum being present in the field during the 2016 season, or to less favorable environmental conditions. Many studies have identified that infected fruit left in the field can serve as a source of inoculum for diseases caused by the same pathogen genera involved in fruit rot of deciduous holly (Harteveld et al. 2014; McKay et al. 2014; Stensvand et al. 2017). Before the establishment of our trial (2016), although disease had occurred in the nursery in the previous year, branches were harvested and many infected fruit, potentially harboring pathogen inoculum, were removed. However, after trial establishment, no branches, including those carrying infected fruit, were harvested. This may explain why higher disease levels were observed in 2017. In addition, several studies have demonstrated that different environmental factors have effects on the relative availability of pathogen inoculum and on host infection (Bassimba et al. 2014; Granke and Hausbeck 2010; King et al. 1997). Environmental conditions in 2016 may have been less conducive to inoculum production or infection development in the field. Further investigations on the identification of potential sources of inoculum in nurseries and the effects of important environmental factors on disease progression are underway and should provide valuable information on understanding the disease cycle(s) and further developing disease management strategies.

In the nursery, a significant increase in fungal isolation frequency (Alternaria and Colletotrichum) was observed right after flowering. Disease symptoms became visible only at the end of the season when the fruit was fully mature and mostly developed from the side of the fruit corresponding to the location of the stigma on the flower. This suggests that infections are initiated during bloom, but fruit colonization occurs only later in the season during fruit ripening, a process that is consistent with the description of a latent infection (Verhoeff 1974).

In the container trials, $D$. ilicicola was the only pathogen that caused disease on mature fruit when inoculated during bloom or petal-fall stage. As observed in the symptomatic fruit samples collected from the nursery, the majority of the rot symptoms developed from the stigmatic end and in a few cases from the calyx end of the fruit. It was also observed that the pathogen could mostly be recovered from the fruit exocarp instead of the mesocarp (data not shown). Thus, the data suggest that $D$. ilicicola infects holly fruit during bloom and remains quiescent in the exocarp until yet undetermined triggering conditions activate the pathogen and cause symptoms to become visible. We speculate that host physiological changes during fruit maturation could play a role in in quiescent pathogen activation.

In our container trials, no disease developed on mature fruit that had been inoculated at any of the flower stages (stage 1 through 3 ) with A. alternata. However, fewer fruit were present on plants that had been inoculated with $A$. alternata during bloom compared with other treatments (data not shown). We suspect that inoculation of flowers with A. alternata may have caused flowers to drop, thereby resulting in fewer of the surviving fruit with infections at the end of the season. Similar results were obtained by Luo et al. (2017), in which no Alternaria heart rot disease developed on pomegranate fruit because most flowers dropped after being inoculated.
Another possible explanation could be that the host environment conditions of deciduous holly fruit did not support Alternaria from exiting quiescence. Even though the majority of the mature fruit samples were found to be colonized by Alternaria spp., the pathogen was retrieved from the lesions on symptomatic fruit in only approximately $4 \%$ of the cases. Other studies have shown or suggested that changes in host physiology during fruit ripening may be related to the activation of A. alternata. On mango fruit Droby et al. (1987) found an association of the antifungal compounds (5-substituted resorcinols) in unripe fruit with the quiescence of A. alternata. In a study on apple core rot caused by A. alternata, Shtienberg (2012) speculated different calcium concentrations in the locule walls of two apple cultivars may be associated with different levels of host susceptibility to infection. Previous studies demonstrated that calcium had inhibitory effects on the activity of polygalacturonase (Biggs et al. 1997; Chardonnet et al. 2000), an enzyme that is secreted by Alternaria during infection (Rotem 1994). All these findings suggest correlations between host physiology and fungal infections.

In both the nursery and container trials, rot symptoms were observed at cool temperatures (below 6.5 and $15.6^{\circ} \mathrm{C}$, respectively), and disease incidence was negatively correlated, in one or both years of the study, to mean maximum temperature (nursery) or mean maximum, minimum, and average temperature (container trials). Although these findings might suggest that exposure to low temperatures could be involved in pathogen activation, the decrease in temperature also coincided with fruit ripening. Based on the data collected in this study, it is not possible to fully understand the role of temperature in disease development. Changes in the physiological properties of deciduous holly fruit during ripening are also currently unknown. Studies to further investigate the factors (host and environment) that terminate quiescence of $A$. alternata and $D$. ilicicola in deciduous holly fruit are underway and will contribute to complementing the observations reported in this study and further understanding this disease.

We previously reported that occasionally two pathogens in the fungal complex, one most frequently being Alternaria, could be isolated from the same fruit lesion (Lin et al. 2018). In the current study, when plants were inoculated with combined Alternaria treatments, infections occurred on wounded mature fruit, but disease incidence was never significantly greater than that caused by the more virulent of the pathogens when it was used alone. Similar results were also observed in a detached fruit inoculation study we previously conducted (Lin et al. 2018). For combined pathogens inoculated at the bloom or petal fall stage, only plants inoculated with A. alternata $+D$. ilicicola developed fruit rot symptoms; however, disease incidence was significantly lower than when D. ilicicola was inoculated alone. A. alternata and Phomopsis mangiferae S. Ahmad were studied on other fruit crops to demonstrate their ability of modulating ambient $\mathrm{pH}$ in the host to enhance pathogenicity (Davidzon et al. 2010; Eshel et al. 2002). A. alternata can secrete ammonia to elevate ambient $\mathrm{pH}$ in melon, pepper, persimmon, and tomato fruit (Eshel et al. 2002). Similarly, gluconic acid is secreted by $P$. mangiferae to lower $\mathrm{pH}$ and enhance its pathogenicity in mango fruit (Davidzon et al. 2010). A. alternata and D. ilicicola in deciduous holly may have contradictory mechanisms to manipulate the host environmental and favor infection, which could be a possible explanation for why lower disease incidence was observed when they were inoculated together. Further studies investigating the factors that activate these pathogens in deciduous holly fruit, including plant nutrition, may provide valuable information for understanding the mechanisms of fungal quiescence and developing appropriate disease management strategies.

In the nursery we observed that mature fruit (stage 5) was frequently injured by either biotic or abiotic factors (e.g., hail, insects, birds, etc.). Therefore, in the container trial, we included a wounded treatment on mature fruit to assess the effects of wounding on disease development. All four pathogens caused fruit rot on wounded fruit, but no disease was observed on unwounded fruit. Although a low level of fruit rot was also observed on noninoculated control plants that had been wounded, disease incidence was negligible compared with all other treatments in both years. Species of Alternaria and 
Epicoccum were isolated from those lesions, which may have been caused by inoculum drift from the inoculated treatments or the presence of natural inoculum in the outdoor environment. This reinforced the concept that some pathogens in the complex could take advantage of the presence of wounds to infect fruit. In the detached fruit inoculation study previously mentioned (Lin et al. 2018), wounded fruit developed significantly higher disease incidence and severity compared with unwounded fruit. Although in that study pathogens were able to also infect unwounded fruit, it should be acknowledged that the assay was conducted under optimal laboratory conditions as opposed to fluctuating environmental conditions of this study. Both studies, however, are in agreement that mature fruit in the field should be protected from any type of wounding to reduce disease levels.

This study provides the first report of latent infection caused by $D$. ilicicola on deciduous holly fruit. Our findings suggest that flowering represents a critical moment to implement disease management practices that target $D$. ilicicola and that mature fruit should be protected from injury to avoid disease. Although many aspects of this disease remain to be investigated, including identification of the sources of pathogen inoculum in the field and host factors and environmental conditions that are conducive to disease development, this research advanced our understanding of the epidemiology of this emerging disease and ultimately facilitates the development of researchbased disease management strategies.

\section{Acknowledgments}

The research described in this paper represents a portion of the dissertation submitted by S. Lin to the Office of Graduate Studies of The Ohio State University to partially fulfill requirements for the Ph.D. degree in plant pathology. The authors thank Dr. J. R. Úrbez-Torres and Dr. G. Marchi for critical review of this manuscript prior to submission.

\section{Literature Cited}

Adaskaveg, J. E., and Hartin, R. J. 1997. Characterization of Colletotrichum acutatum isolates causing anthracnose of almond and peach in California. Phytopathology 87:979-987.

Barnett, H. L., and Hunter, B. B. 1998. Illustrated Genera of Imperfect Fungi, 4th Ed. APS Press, St. Paul, MN.

Bassimba, D. D. M., Mira, J. L., and Vicent, A. 2014. Inoculum sources, infection periods, and effects of environmental factors on Alternaria brown spot of mandarin in Mediterranean climate conditions. Plant Dis. 98:409-417.

Baumgartner, K., Fujiyoshi, P. T., Travadon, R., Castlebury, L. A., Wilcox, W. F., and Rolshausen, P. E. 2013. Characterization of species of Diaporthe from wood cankers of grape in eastern North American vineyards. Plant Dis. 97: 912-920.

Biggs, A. R., El-Kholi, M. M., El-Neshawy, S., and Nickerson, R. 1997. Effects of calcium salts on growth, polygalacturonase activity, and infection of peach fruit by Monilinia fructicola. Plant Dis. 81:399-403.

Binyamini, N., and Schiffmann-Nadel, M. 1972. Latent infection in avocado fruit due to Colletotrichum gloeosporioides. Phytopathology 62:592-594.

Chardonnet, C. O., Sams, C. E., Trigiano, R. N., and Conway, W. S. 2000. Variability of three isolates of Botrytis cinerea affects the inhibitory effects of calcium on this fungus. Phytopathology 90:769-774.

Davidzon, M., Alkan, N., Kobiler, I., and Prusky, D. 2010. Acidification by gluconic acid of mango fruit tissue during colonization via stem end infection by Phomopsis mangiferae. Postharvest Biol. Technol. 55:71-77.

Daykin, M. E., and Milholland, R. D. 1984. Infection of blueberry fruit by Colletotrichum gloeosporioides. Plant Dis. 68:948-950.

Dissanayake, A. J., Liu, M., Zhang, W., Chen, Z., Udayanga, D., Chukeatirote, E., Li, X. H., Yan, J. Y., and Hyde, K. D. 2015. Morphological and molecular characterization of Diaporthe species associated with grapevine trunk disease in China. Fungal Biol. 119:283-294.

Droby, S., Prusky, D., Jacoby, B., and Goldman, A. 1987. Induction of antifungal resorcinols in flesh of unripe mango fruits and its relation to latent infection by Alternaria alternata. Physiol. Mol. Plant Pathol. 30:285-292.

Eshel, D., Miyara, I., Ailing, T., Dinoor, A., and Prusky, D. 2002. pH regulates endoglucanase expression and virulence of Alternaria alternata in persimmon fruit. Mol. Plant-Microbe Interact. 15:774-779.

Galle, F. C. 1997. Hollies: The Genus Ilex. Timber Press, Portland, OR.

Granke, L. L., and Hausbeck, M. K. 2010. Influence of environmental on airborne spore concentrations and severity of asparagus purple spot. Plant Dis. 94: $843-850$.
Halfon-Meiri, A., and Rylski, I. 1983. Internal mold caused in sweet pepper by Alternaria alternata: Fungal ingress. Phytopathol. 73:67-70.

Harteveld, D. O. C., Akinsanmi, O. A., Chandra, K., and Drenth, A. 2014. Timing of infection and development of Alternaria diseases in the canopy of apple trees. Plant Dis. 98:401-408.

Holb, I. J., and Scherm, H. 2007. Temporal dynamics of brown rot in different apple management systems and importance of dropped fruit for disease development. Phytopathology 97:1104-1111.

Humber, R. A. 1997. Pages 269-279 in: Fungi: Preservation of Cultures. Manual of Techniques in Insect Pathology. L. A. Lacey, ed. Academic Press, London

Johnson, G. I., Mead, A. J., Cooke, A. W., and Dean, J. R. 1992. Mango stem end rot pathogens - Fruit infection by endophytic colonization of the inflorescence and pedicel. Ann. Appl. Biol. 120:225-234.

King, W. T., Madden, L. V., Ellis, M. A., and Wilson, L. L. 1997. Effects of temperature on sporulation and latent period of Colletotrichum spp. infecting strawberry fruit. Plant Dis. 81:77-84.

Li, Y. C., Bi, Y., and An, L. Z. 2007. Occurrence and latent infection of Alternaria rot of Pingguoli pear (Pyrus bretschneideri Rehd. cv. Pingguoli) fruits in Gansu, China. J. Phytopathol. 155:56-60.

Lin, S., Taylor, N. J., and Peduto Hand, F. 2018. Identification and characterization of fungal pathogens causing fruit rot of deciduous holly. Plant Dis. doi:10.1094/ PDIS-02-18-0372-RE

Luo, Y., Hou, L., Förster, H., Pryor, B., and Adaskaveg, J. E. 2017. Identification of Alternaria species causing heart rot of pomegranates in California. Plant Dis. 101:421-427.

Mahadevakumar, S., Jayaramaiah, K. M., and Janardhana, G. R. 2014. First report of leaf spot disease caused by Epicoccum nigrum on Lablab purpureus in India. Plant Dis. 98:284.

McKay, S. F., Shtienberg, D., Sedgley, M., and Scott, E. S. 2014. Anthracnose on almond in Australia: Disease progress and inoculum sources of Colletotrichum acutatum. Eur. J. Plant Pathol. 139:773-783.

Moral, J., and Trapero, A. 2012. Mummified fruit as a source of inoculum and disease dynamics of olive anthracnose caused by Colletotrichum spp. Phytopathol. 102:982-989.

Nemsa, I., Bouzid, S., Hernandez, M. A., Lacasa, A., Porras, I., Garcia-Lidon, A., Cifuentes, D., Bouzid, S., Ortuno, A., and Del, R. J. A. 2012. Pathogenicity of Alternaria alternata on fruits and leaves of 'Fortune' mandarin (Citrus clementine $\times$ Citrus tangerina). Can. J. Plant Pathol. 34:195-202.

Ohsawa, T., and Kobayashi, T. 1989. Concave rot of melon fruit caused by two Phomopsis fungi. Jpn. J. Phytopathol. 55:410-419.

Olatinwo, R. O., Hanson, E. J., and Schilder, A. M. C. 2003. A first assessment of the cranberry fruit rot complex in Michigan. Plant Dis. 87:550-556.

Prusky, D., Ben-Arie, R., and Guelfat-Reich, S. 1981. Etiology and histology of Alternaria rot of persimmon fruits. Phytopathol. 71:1124-1128.

Prusky, D., Fuchs, Y., and Yanko, U. 1983. Assessment of latent infections as a basis for control of postharvest disease of mango. Plant Dis. 67:816-818.

Rotem, J. 1994. The Genus Alternaria: Biology, Epidemiology, and Pathogenicity APS Press, St. Paul, MN.

Shivas, R. G., and Tan, Y. P. 2009. A taxonomic re-assessment of Colletotrichum acutatum, introducing $C$. fioriniae comb. et stat. nov. and $C$. simmondsii $\mathrm{sp}$ nov. Fungal Divers. 39:111-122.

Shtienberg, D. 2012. Effects of host physiology on the development of core rot, caused by Alternaria alternata, in Red Delicious apples. Phytopathol. 102:769-778.

Simmons, E. G. 2007. Alternaria: An Identification Manual. CBS Fungal Biodiversity Centre, Utrecht, The Netherlands.

Stensvand, A., Stensvand, A., Borve, J., and Talgo, V. 2017. Overwintering diseased plant parts and newly infected flowers and fruit as sources of inoculum for Colletotrichum acutatum in sour cherry. Plant Dis. 101 1207-1213.

Udayanga, D., Castlebury, L. A., Rossman, A. Y., Chukeatirote, E., and Hyde, K. D. 2014. Insights into the genus Diaporthe: Phylogenetic species delimitation in the D. eres species complex. Fungal Divers. 67:203-229.

Velho, A., Alaniz, S., Casanova, L., Mondino, P., and Stadnik, M. 2015. New insight into the characterization of Colletotrichum species associated with apple diseases in southern Brazil and Uruguay. Fungal Biol. 119:229-244

Verhoeff, K. 1974. Latent infections by fungi. Annu. Rev. Phytopathol. 12:99-110.

Verma, N., MacDonald, L., and Punja, Z. K. 2007. Environmental and host requirements for field infection of blueberry fruits by Colletotrichum acutatum in British Columbia. Plant Pathol. 56:107-113.

Wu, D., Zhang, D. H., Timko, M. P., Li, M. Y., and Liang, G. L. 2017. First report of Epicoccum nigrum causing brown leaf spot of loquat in Southwestern China Plant Dis. 101:1553.

Zaitlin, B., Zehr, E. I., and Dean, R. A. 2000. Latent infection of peach caused by Colletotrichum gloeosporioides and Colletotrichum acutatum. Can. J. Plant Pathol. 22:224-228. 